\title{
Moving genomics from discovery to development
}

While drug approval times have decreased, clinical development times continue to rise. Some of this increase is due to regulatory bureaucracy, some due to the need to provide more elaborate documentation to healthcare providers, and some due to bad clinical trial design and management. But certainly a good part of the problem is that the drugs now in development are targeted to the multifactorial diseases of chronic illness and aging, so that trials are of necessity much more complex, expensive, and time-consuming.

The situation is all the more pressing because drug pipelines are now brimming with leads, thanks in large part to the application of genomics to discovery. Now, pharmacogenomics-the molecular study of the genetic factors that determine drug efficacy and toxicity, born out of pharmacogenetics and spurred forward by the data churning out of the Human Genome Project-promises to cut development times the way these technologies have already helped accelerate the drug discovery process. It is featured in this issue (pp. 925 and 954) and the next because it is going to have an enormous impact on how the business of drug development is done.

The application of these technologies will help identify with greater precision which drug leads should enter the development process and which populations of patients they should be administered to, thereby reducing costs and time. Some pharmaceutical companies are already incorporating screening for drug metabolism enzymes, such as cytochrome $\mathrm{P} 450$ s, into their preclinical programs. Others, such as SmithKline Beecham and its new spinout diaDeXus (see p. 937), have much grander ambitions, incorporating pharmacogenetic variation into discovery, clinical development, and the design of diagnostics and prognostics.
It is easy to overplay the genetic variation card in drug development--there are many other equally important factors in developing safe and efficacious medicines. But drug makers ignore this information at their peril. It would be foolish indeed to carry out a clinical trial for a drug in Alzheimer's disease without stratifying the population according to ApoE genotype. Pharmacogenomic studies with the Alzheimer's drug Parke-Davis's drug Cognex (tacrine) have already revealed that a subset of patients who do not have the APOE4 genotype respond better to the drug than those who do. And how useful would it have been for Wyeth-Ayerst and Interneuron to be able to screen for a subpopulation genetically predisposed to adverse cardiac effects before they put fenfluramine and dexfenfluramine on the market.

With pharmacogenomics comes many opportunities, as demonstrated by the deal at the end of July between Gensett and Abbott Laboratories (Nature Biotechnology 15:829, 1997). It will be of use to pharmaceutical companies trying to find new indications for existing drugs. And it may make it possible to resurrect failed drugs that may only have failed because they were administered to the wrong group of people. In addition to helping identify therapeutics with which to treat disease signs and symptoms, pharmacogenomics should ultimately help cut a path to the medicine of individualized prediction and prevention.

In the meantime, perhaps the biggest advantage for companies attempting to use pharmacogenomics is that it isn't always necessary to know the function of the target gene to be able to develop tests to help stratify a population for trial design. And with this knowledge, biotechnology companies can momentarily bypass the biggest problem of all in genomics-determining function.

\section{"Solutions" companies supply answers}

In the days when biotechnology companies wanted to grow up to become product companies (about 10 years ago-you remember), laboratory supply companies knew their place. It was to apply professionalism to the provision of technical tools, putting researchers' "useful widgets" like restriction endonucleases or chromatographic media on a commercial footing. Supply companies prided themselves on assuring quality of product and constancy of supply. They were content to be packagers of ideas in boxes, and distributors of ready-to-use technical advances for the research community. They supplied their wares to all layers of the biotechological food chain-academic researchers, research-based companies, and multinationals. Their job in the general furtherance of biotechnology was clear; it was to help propel small companies toward the market by selling them equipment and reagents that would save time.

Times change, of course, and so do companies. Many biotechnology companies have curtailed their ambitions somewhat. They no longer expect to develop, manufacture, and market their own products-not soon, at least. They have adopted a service ethic, gleaning cash from pharmaceutical and agrochemical companies in exchange for very specialized chunks of knowledge or access to particularly useful molecular tools. In essence, they moved substantially toward the traditional supply companies, building another layer of expertise on relatively widely available high-technology tools.
The latest trend sees the supply companies move still closer to the biotechnology companies. Suppliers are becoming "solutions" companies, addressing implicit "problems" within biotechnology and pharmaceutical organizations. Solutions companies enter into fewer, more intimate relationships than supply companies. Their customers are "clients." This intimacy means that needs (and appropriate solutions) are identified and developed jointly by both parties.

The "solutions" arrival of this philosophy has necessitated mergers and acquisitions among suppliers: Pharmacia Biotech and Amersham Life Science announced their merger in mid-June and will operate as Amersham Pharmacia Biotech from the beginning of October; PerkinElmer bought Perseptive Biosystems for $\$ 360$ million in stock at the end of August; and at the beginning of September, Beckman Instruments spent $\$ 875$ million to acquire Coulter Corporation and its $\$ 175$ million debts. The mergers are necessary, of course, to enable companies to provide "solutions" rather than merely "a solution" or "partial solutions."

With large companies now comfortably ensconced in the marketplace and erstwhile supply companies nearing the scientific cutting edge in order to provide the best "solutions," the commercial space within which biotechnology companies operate is going to become narrower. They will need to redefine themselves. Offering single platform technologies will no longer be enough to differentiate them from the "solutions" companies. 